\title{
OPTIMAL DESIGN OF E-SERVICES: A ROBUST APPROACH
}

\author{
Francesco MORESINO \\ Geneva School of Business Administration, HES-SO, Switzerland \\ francesco.moresino@hesge.ch
}

\begin{abstract}
Service design optimizers benefited greatly from the development of conjoint analysis, which appeared more than forty years ago. Conjoint analysis is a powerful and popular method to estimate consumers' preferences. As this method is based on a survey, the estimated utility functions can be subject to inaccuracies. In this paper, we propose a service design optimizer that combines robust programming and conjoint analysis. This permits one to identify the optimal service, even when the utility functions are subject to uncertainties.
\end{abstract}

Keywords: Conjoint analysis, robust optimisation, service design, service pricing, share-ofchoice model.

JEL classification: D41, C44, C61.

DOI: $10.12948 / \mathrm{ie} 2019.07 .02$

\section{Introduction}

Service design optimisers benefited greatly from the development of conjoint analysis, which appeared in the seventies. Zufryden [1] was the first to propose a service design optimiser based on conjoint analysis. His model maximises the share-of-choice and is formulated as a mixed integer linear program. Later, Easton and Pullman [2] seem to be the firsts who augmented a share-of-choice model in order to take into account some aspects of production. This approach has been further developed by Fragnière and colleagues [3, 4], where a meta-model combining a share-of-choice model with a production model permits one to design and price a service in an optimal way. This method combines conjoint analysis with operations research and has been successfully used to tackle problems in different domains [5-10]. Unfortunately, this method has a major drawback for non-specialists. Indeed, to be able to construct the model, solid knowledge in operations research are necessary. However, a synthetic model was proposed recently in [11]. This model, named profit-of-choice, permits even non-specialists to use the method as no modelling is necessary. Conjoint analysis is a popular method to estimate consumers' preferences. As this method is based on a survey, the estimated utility functions can be subject to inaccuracies. In order to take into account such inaccuracies, Wang and Curry [12] proposed a robust approach to the share-of-choice problem. This permits one to take the best decision, even when the utility functions are subject to uncertainties.

In the present paper, we propose to combine the profit-of-choice method of [11] with the robust approach of [12]. Doing so, we obtain a service design optimiser that permits one to take into account in a robust way, uncertainties about the utility functions.

The paper is organised as follows. In section 2, we recall the robust approach to the share-ofchoice model proposed in [12]. Then, in section 3, we present the robust services design optimiser. In section 4, a case study in the domain of e-services is introduced and numerical results are shown. Finally, in section 5, we conclude and present directions for further research. 
www.conferenceie.ase.ro

\section{A robust share-of-choice}

In this section, we present the robust approach to the share-of-choice problem proposed by Wang and Curry [12]. For the algebraic formulation of the model, we use the following sets.

Respondent $\quad \mathrm{k}=1 \ldots \mathrm{K}$.

Attribute $\quad \mathrm{i}=1 \ldots \mathrm{I}$.

Level of attribute $\quad j=1 \ldots \mathrm{J}_{\mathrm{i}}$.

To keep notation simpler and to follow the formalism of [12], we suppose, without loss of generality, that the utility functions are positive. The share-of-choice constraints write then

$$
\sum_{i=1}^{I} \sum_{j=1}^{J_{i}} u(k, i, j) \cdot X(i, j) \geq\left(u_{c}(k)+u_{m}(k)\right) \cdot Y(k) \quad \forall k .
$$

The part-worth, $\mathrm{u}(\mathrm{k}, \mathrm{i}, \mathrm{j})$ represents the utility perceived by respondent $\mathrm{k}$ if attribute $\mathrm{i}$ is set to level $\mathrm{j} . \mathrm{u}_{\mathrm{c}}(\mathrm{k})$ is the current utility, for respondent $\mathrm{k}$, provided by the competition and $\mathrm{u}_{\mathrm{m}}(\mathrm{k})$ the minimum increase of utility to turn respondent $\mathrm{k}$ into a consumer. $\mathrm{X}(\mathrm{i}, \mathrm{j})$ is the service configuration. $X(i, j)=1$ if attribute $i$ is set to level $j$ and $X(i, j)=0$ otherwise. $Y(k)$ is the preference for respondent $\mathrm{k} . \mathrm{Y}(\mathrm{k})=1$ if respondent $\mathrm{k}$ becomes a new client and $\mathrm{Y}(\mathrm{k})=0$ otherwise.

Let $\mathrm{F}$ be the number of coefficients subject to uncertainties in each constraint. We suppose that the uncertain part-worths lie in the interval

$[u(k, i, j)-\bar{u}(k, i, j) ; u(k, i, j)+\bar{u}(k, i, j)]$

where $\bar{u}(k, i, j)$ is the error term. Then, to incorporate these errors, the share-of-choiceconstraints, are replaced with the following constraints

$$
\begin{gathered}
\sum_{i=1}^{I} \sum_{j=1}^{J_{i}} u(k, i, j) \cdot X(i, j)-\left(F \cdot Q(k)+\sum_{i=1}^{I} \sum_{j=1}^{J_{i}} B(k, i, j)\right) \\
\geq\left(u_{c}(k)+u_{m}(k)\right) \cdot Y(k) \quad \forall k . \\
Q(k)+B(k, i, j) \geq \bar{u}(k, i, j) \cdot X(i, j) \quad \forall k, i, j . \\
Q(k) \geq 0 \quad \forall k . \\
B(k, i, j) \geq 0 \quad \forall k, i, j .
\end{gathered}
$$

\section{The model}

In this section, we propose an extension of the profit-of-choice model proposed in [11] in order to take into account in a robust way uncertainties about the utility coefficients.

Let $\mathrm{i}=1$, be the attribute for the price. We denote with $\pi(\mathrm{j})$, the service price for level $\mathrm{j}$. Production costs are split in fixed costs and variable costs. Let $c_{f}(i, j)$ be the fixed costs if the attribute $\mathrm{i}$ is set to level $\mathrm{j}$. Let $\mathrm{c}_{\mathrm{v}}(\mathrm{i}, \mathrm{j})$ be the corresponding variable costs. For each attribute $\mathrm{i}$, we must have the normalization 
www.conferenceie.ase.ro

$$
\sum_{j=1}^{J_{i}} X(i, j)=1 \quad \forall i
$$

These equations insure that each attribute is set to one and only one level. Let $w(k)$ be the weight of respondent $\mathrm{k}$. Then the market share writes

$$
S=\frac{\sum_{k=1}^{K} w_{k} \cdot Y(k)}{\sum_{k=1}^{K} w_{k}}
$$

The fixed costs are computed as follows:

$$
C_{f}=\sum_{i=1}^{I} \sum_{j=1}^{J_{i}} c_{f}(i, j) \cdot X(i, j) .
$$

In order to preserve the linear property, we have to write the variable costs with an indirect method. Let $\mathrm{C}_{\mathrm{v}}$ (i) be the variable cost associated with the attribute i. Then, we must have

$$
\begin{array}{ll}
C_{v}(i) \geq S \cdot d \cdot c_{v}(i, j)-(1-X(i, j)) \cdot M & \forall i, j, \\
C_{v}(i) \leq S \cdot d \cdot c_{v}(i, j)+(1-X(i, j)) \cdot M & \forall i, j,
\end{array}
$$

where $\mathrm{M}$ is a big number and $\mathrm{d}$ the demand. These inequalities insure that the variable costs are proportional to the market share S. Similarly, to keep the model linear, we must formulate the revenues, noted $\mathrm{R}$, as follows:

\begin{tabular}{|ll|l|}
\hline$R \leq S \cdot d \cdot \pi(j)+(1-X(1, j)) \cdot M$ & $\forall j \in\left\{1, \ldots, I_{1}\right\}$, & $(12)$ \\
\hline$R \geq S \cdot d \cdot \pi(j)-(1-X(1, j)) \cdot M$ & $\forall j \in\left\{1, \ldots, I_{1}\right\}$. & $(13)$ \\
\hline
\end{tabular}

Finally, the objective is to maximise profits:

$$
\max _{X} R-C_{f}-\sum_{i=1}^{I} C_{v}(i)
$$

The system (3)-(14) describes our robust profit-of-choice model and is a mixed integer program that can be solved with standard techniques. When we maximise profits, (11) and (13) are never binding and can be discarded from the model.

\section{Case study}

To illustrate the method, we take the case study proposed in [11]. This case study aims to design the combined package proposing phone, internet and television for a provider entering a market where one competitor is present. The model is kept small and easy for didactical reasons. The service has four salient attributes, namely price, TV offer, internet speed, and phone offer. The levels considered for the design are given in table 1. Currently, the competition offers a 
combined package including gold TV, fast internet and basic phone at a price of 29 euros. Data for this model are the same as in [11].

Table 1. Salient attributes and their levels.

\begin{tabular}{ccc}
\hline Attribute & Attribute level & Description \\
\hline \multirow{3}{*}{ Price } & 19 & monthly price: 19 euros \\
& 29 & monthly price: 29 euros \\
& 39 & monthly price: 39 euros \\
& 49 & monthly price: 49 euros \\
\hline \multirow{3}{*}{ TV offer } & silver & no replay and no recording possibilities \\
& gold & replay but no recording possibilities \\
& platinum & replay and recording possibilities \\
\hline \multirow{2}{*}{ Internet speed } & slow & 40 Mbit/sec \\
& fast & 1 Gbit/sec \\
\hline \multirow{2}{*}{ Phone offer } & basic & no conversation included \\
& premium & unlimited conversation included
\end{tabular}

For the uncertainties, we chose a conservative value $\mathrm{F}=4$ and homogenous error terms $\bar{u}(k, i, j)=1$. We modelled this case study with the language AMPL and used the solver Mosek. The optimal design for both the robust case and the non-robust case are given in table 2 , whereas the profits and market shares are given in table 3.

Table 2. Optimal service design.

\begin{tabular}{c|cc}
\hline Attribute & Robust case & Non-robust case \\
\hline Price & 29 & 39 \\
TV offer & platinum & platinum \\
Internet speed & slow & fast \\
Phone offer & premium & premium \\
\hline
\end{tabular}

Table 3. Profits and market share for both approaches.

\begin{tabular}{ccccc}
\hline & \multicolumn{2}{c}{ normal case scenario } & \multicolumn{2}{c}{ worst case scenario } \\
& profit & market share & profit & market share \\
\hline $\begin{array}{c}\text { robust approach } \\
\text { non-robust } \\
\text { approach }\end{array}$ & 248 & $60 \%$ & -384 & $20 \%$ \\
\hline
\end{tabular}

For this case study, we see that the robust approach leads to a more prudential strategy. The non-robust is clearly in the upmarket segment with a high price whereas the robust approach leads to an offer in the midmarket with a low price. As expected, in the presence of inaccurate part-worths, the robust method outperforms a direct approach. 
www.conferenceie.ase.ro

In this paper, in order to keep the model as simple as possible, we considered the case with a single competitor and a single service. Albeit we did not do so, the method can tackle multiple competitors as well as the possibility to design simultaneously several services.

\section{Conclusions}

In this paper, we presented a new service design optimiser that takes into account the uncertainties of the utility functions. The model is a robust extension of the profit-of-choice model proposed in [11]. We illustrate the method with a case study in the domain of e-services. For further research, we aim to develop a version that will take into account uncertainties about the demand. This will be achieved, using a stochastic programming approach.

\section{Acknowledgment}

This research was supported by a grant from RCSO Economie \& Management, HES-SO.

\section{References}

[1] F. S. Zufryden, "A conjoint measurement-based approach for optimal new product design and market segmentation" in Analytic Approaches to Product and Marketing Planning: Proceedings of Workshop (A. Shocker, ed.), pp. 100 - 114, Marketing Science Institute, 1977.

[2] F. F. Easton and M. E. Pullman, "Optimizing service attributes: The seller's utility problem”, Decision Sciences, vol. 32, no. 2, pp. 251-276, 2001.

[3] J. Deb'ely, M. Dubosson, and E. Fragni ere, "The pricing of knowledge-based services: Insights from the environmental sciences", Journal of Services Research, Special issue, pp. 167-181, 2008.

[4] E. Fragni 'ere, C. Heitz, and F. Moresino, "The concept of shadow price to monetarize the intangible value of expertise" in Proceedings of the IEEE International Conference on Service Operations and Logistics, and Informatics, 2008, pp. 1736-1741, IEEE, 2008.

[5] E. Fragni'ere, F. Moresino, and N. Zheng, "Development of pricing models for intangible services based on conjoint analysis and mathematical programming: A case study about the design of credit card services in China" in IEEE Proceedings of the Service Research and Innovation Institute Conference, pp. 653-662, IEEE, 2011.

[6] E. Fragni 'ere, F. Moresino, and Y. Shen, "Application of share of choice model in insurance industry based on conjoint analysis and mathematical programming" in Proceedings of the IEEE International Conference on Service Operations and Logistics, and Informatics, pp. 404-409, IEEE, 2012.

[7] E. Fragni ere, A. Lombardi, and F. Moresino, "Designing and pricing services based on customer-perceived value: An airline company feasibility study", Service Science, vol. 4, no. 4, pp. 320-330, 2012.

[8] F. Moresino, E. Fragni'ere, R. Kanala, A. Reveiu, and I. Smeureanu, "Coupling technoeconomic energy models with a share of choice" in Proceedings of the IE2015 International Conference, pp. 443-448, 2015.

[9] E. Fragni 'ere, R. Kanala, F. Moresino, A. Reveiu, and I. Smeureanu, "Coupling technoeconomic energy models with behavioral approaches", Operational Research, vol. 17, no. 2, pp. 633-647, 2017.

[10] F. Moresino, E. Fragni 'ere, "Combining Behavioral Approaches with Techno-Economic Energy Models: Dealing with the Coupling Non-Linearity Issue", Energies, vol.11, no 7, pp. 1-14, 2018. 
[11] F. Moresino, "Optimal design and pricing of e-services", Proceedings of the IE2017 International Conference, pp. 396-401, 2017.

[12] X. Wang and D. J. Curry, "A robust approach to the share-of-choice product design problem”, Omega, vol. 40, no. 6, pp. 818-826, 2012. 